\title{
13
}

\section{Continuous Distributed Modeling for Evaluation of Stormwater Quality Impacts from Urban Development}

\author{
Baxter E. Vieux and Jean E. Vieux
}

Understanding the impact of land use changes on nutrient and sediment loading from stormwater runoff to a water supply reservoir is the motivation for the study referenced in this chapter. Changes in the loading rate and the relative proportion of nutrients, e.g. nitrogen and phosphorus, can have important effects on eutrophication and algae production in the receiving water of the lake. Evaluation of stormwater runoff quantity and quality is performed for the $30.8 \mathrm{~km}^{2}\left(11.9 \mathrm{mi}^{2}\right)$ Rock Creek watershed located within the corporate limits of the City of Norman, OK. This watershed is part of the larger drainage area of Lake Thunderbird reservoir, which is operated by the Central Oklahoma Master Conservancy District and supplies drinking water to Norman and two other surrounding communities. The reservoir was constructed by the US Bureau of Reclamation in 1961-1965. The 2001 bathymetric survey determined Lake Thunderbird to have a maximum depth of $58 \mathrm{ft}(17.7 \mathrm{~m})$, mean depth of $15.4 \mathrm{ft}(4.7 \mathrm{~m})$, surface area of 5,439 acres $(2,211 \mathrm{ha})$ and volume of 105,838 acre-feet $\left(130,180,000 \mathrm{~m}^{3}\right)$. Excessive algae production leads to taste and odor complaints about the finished water product.

Continuous simulation, using the physics-based distributed hydrologic model $\mathrm{V} f l o^{\mathrm{TM}}$, is used to identify runoff and loading rates for three development scenarios. $\mathrm{V} f l{ }^{\mathrm{TM}}{ }^{\mathrm{M}}$ is a commercial model that has been available

Vieux, B. and J. Vieux. 2007. "Continuous Distributed Modeling for Evaluation of Stormwater Quality Impacts from Urban Development." Journal of Water Management Modeling R227-13. doi: 10.14796/JWMM.R227-13. (C) CHI 2007 www.chijournal.org ISSN: 2292-6062 (Formerly in Contemporary Modeling of Urban Water Systems. ISBN: 0-9736716-3-7) 
since 2001. Distributed maps of topography, soils, and land use/cover represent the watershed surface characteristics at a model resolution of $60 \mathrm{~m}$. Sample concentrations for selected water quality parameters have been tested at four locations within the watershed by the Oklahoma Water Resources Board. Sample concentrations are compared to the EMC values reported in the National Stormwater Quality Database, NSQD, reported in Maestre and Pitt (2005) and Pitt et al. (2003). While many constituents are within one standard deviation about the median, others are elevated at several locations within the watershed. Further comparisons are made for additional events for purposes of verification and evaluation of nutrients associated with the range of land use conditions and development found within the watershed.

Three scenarios are modeled for purposes of estimating potential impacts: (i) baseline conditions, (ii) two-thirds conversion to low-density housing; and (iii) full conversion. The baseline development scenario evaluated is consistent with the Norman 2025 planned land use. Future development scenarios consider build-out from country residential to low density housing. To represent each scenario, changes in the distributed model are made within specific areas of the watershed. Representation of the development scenarios within the model includes: (i) increased imperviousness; (ii) reduced hydraulic roughness due to developed surfaces; and (iii) changes in event mean concentration (EMC) for selected nutrients and other constituents. The three development scenarios are simulated under long-term continuous (1994-2005) conditions, design storms, and for specific events using precipitation input derived from rain gauge and radar.

This chapter presents the assessment of water quality impacts due to projected urban development using a fully distributed hydrologic model. The organization of this chapter begins with the methodology, input data, and study area, followed by results, discussion and summary sections.

\subsection{Methodology}

\subsubsection{Study Area}

The Rock Creek Watershed is located near Norman, Oklahoma and in the tributary area of the Lake Thunderbird reservoir, which serves purposes of water supply, recreation, and flood control. Concerns over eutrophication and impacts of urban development prompted this study. Rock Creek 
watershed is contained within the city limits of Norman in Central Oklahoma. The drainage area is $30.8 \mathrm{~km}^{2}\left(11.9 \mathrm{mi}^{2}\right)$. There is an elevation difference of about $45 \mathrm{~m}$ over the 11,265-m main channel, resulting in an average slope of $0.4 \%$. Soils under natural conditions have an estimated average hydraulic conductivity of $0.71 \mathrm{~cm} / \mathrm{hr}$, and an average soil depth of $22 \mathrm{~cm}$. This watershed is characterized as $79 \%$ pasture and open space, and $21 \%$ residential and commercial land use. While the current residential density is in conformance with the Norman 2025 plan, conversion from lowdensity country residential to higher density developments is taking place in Rock Creek and surrounding watersheds.

\subsubsection{Distributed Model Setup}

The distributed physics-based model, $\mathrm{V} f \mathrm{fl}^{\mathrm{TM}}$, is setup and parameterized using geospatial data representing terrain, soils, land use/cover, and impervious areas where developed surfaces limit infiltration. The model solves the kinematic wave equations by numerical solution of conservation equations. It is parameterized by physical characteristics of the soils, land use/cover, and topography using geospatial data. Model inputs are principally derived from radar and gauge precipitation measures with application in urban watersheds, which is described in Vieux and Bedient (2004). Evapotranspiration is modeled using climatological rates modified to represent actual conditions limited by occurrence of rainfall and limitations imposed by available soil moisture. The resulting model is applicable in urban and rural watersheds that range in scale from headwaters to rivers. Model setup with geospatial data relies on GIS and commonly available geospatial datasets such as digital terrain, land use/cover from satellite remote sensing, and maps of soil properties and depth. Refinement of the model is accomplished using distributed model calibration procedures developed and described by Vieux and Moreda (2003) and Vieux (2004). Model characteristics are described as follows.

1. Model Background. Real-time $\mathrm{V} f \mathrm{fl}^{\mathrm{TM}}$ uses maps of data and laws of physics to solve equations that forecast flooding. The system is designed to track distributed soil moisture and runoff automatically in an unattended mode with information accessible via an intra/internet web browser. An abridged description of the model setup and data required are as follows. Geospatial data is used to setup $\mathrm{V} f l o^{\mathrm{TM}}$ starting with a digital elevation model (DEM) for derivation of slope and flow direction (D8 or D4); 
remotely sensed land use/cover for overland hydraulic roughness; impervious area and soil characteristics for derivation of Green and Ampt infiltration parameters and soil depth; channel geometry and hydraulic characteristics.

2. Precipitation Inputs. Rainfall and snowmelt may be input on a gridded-basis as maps, or input as uniformly distributed rainfall rates/accumulations. Distributed precipitation formats that are supported include formats generated by radars in the US and internationally. Point hyetographs may be input for subareas such as basins or uniformly over the entire domain. Snowmelt is modeled on a distributed basis using the temperature index method.

3. Runoff Routing. The kinematic wave equations are solved on a grid cell basis within a drainage network composed of finite elements. The formulas are adapted to represent overland and channel hydraulics. Floodplain storage effects can be simulated using the Modified Puls method to account for attenuation due to temporary storage. Complex channel hydraulics are represented by: (i) rating curves for stage area/discharge, (ii) surveyed channel cross-sections with slope and Manning's roughness, and (iii) trapezoidal cross-sections with slope and Manning's roughness.

4. Soil Moisture and Infiltration. The theoretical basis of the infiltration module is the Green and Ampt equation, which relies on the soil properties. Infiltration-rate excess runoff is computed in each grid cell as a function of soil properties and antecedent conditions. Once the soil moisture storage capacity is filled, then saturation excess runoff is computed. When the soil moisture is modeled over time, the infiltration rate is adjusted to account for a range of soil moisture. Impervious area and initial abstraction may be set to account for urbanization effects and ponding on the land surface. The rate of soil moisture depletion is limited by the climatological evapotranspiration (ET) rate and available soil moisture.

5. Distributed Output. A feature unique to distributed models is the capability to output distributed runoff and other hydrologic quantities at any location. This capability supports generation of hydrographs at locations selected in the drainage network regardless of current watershed 
delineations. Because the model outputs stage at distributed locations along the channel, inundation mapping can be accomplished that is more detailed than routing in channel reaches.

\subsubsection{Urban Development Scenarios}

Projection of water quality effects associated with future urbanization scenarios follows a scheme whereby three levels of development are compared with baseline (current) conditions. The current land use categories that represent baseline conditions are shown in Figure 13.1. The percentage of baseline land use categories expressed as a percentage of overall watershed area is presented in Table 13.1.

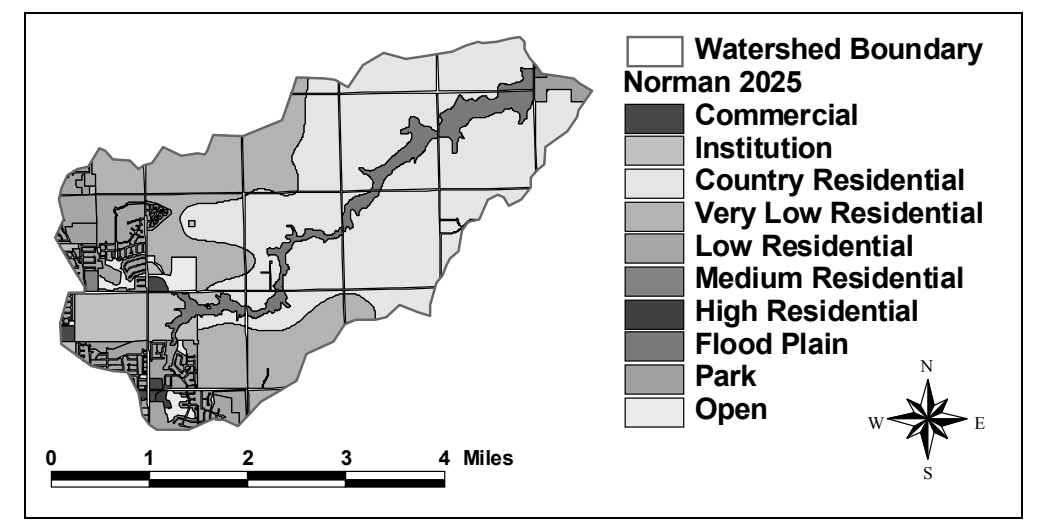

Figure 13.1 Baseline land use categories in Rock Creek.

The modeled scenarios are represented by applying the appropriate model parameters in the watershed, which are imperviousness and hydraulic roughness model parameters. Mean values of these parameters are presented in Table 13.2. The scenarios are established based on (i) development in the upper one third, (ii) extended to two thirds, and (iii) full development in the entire watershed. For each scenario, the hydraulic roughness and imperviousness are arrived at by digitizing from aerial photography the rooftops, streets, and other impervious surfaces in areas typical of developed tracts in the watershed. Once the imperviousness and roughness are 
established for developed areas such as housing developments, commercial and industrial tracts, and streets, the same conditions are applied to the watershed area in the upper one third, two thirds, and full watershed areas. This scheme was selected because it follows the development pattern that has already taken place in the upper third of the watershed.

Table 13.1 Land use percentages of total watershed area.

\begin{tabular}{lc}
\hline Land Use & Area (\%) \\
\hline Commercial & 1 \\
Country residential & 48 \\
Flood Plain & 6 \\
High Density Residential & 0.1 \\
Institutional & 5 \\
Low Density Residential & 10 \\
Medium Density Residential & 0.2 \\
Open & 2 \\
Parks (Public sector) & 2 \\
Very Low Density Residential & 21 \\
\hline
\end{tabular}

Table 13.2 Model parameters applied to the watershed in the scenarios.

\begin{tabular}{ccc}
\hline Land use & Imperviousness & Roughness \\
\hline Baseline & $9.4 \%$ & 0.030 \\
Scenario 1 & $16.8 \%$ & 0.028 \\
Scenario 2 & $23.5 \%$ & 0.026 \\
Scenario 3 & $31.2 \%$ & 0.024 \\
\hline
\end{tabular}

\subsubsection{Distributed Model Setup and Rainfall Input}

At a model resolution of 60-m (197-ft), 8,363 cells are used to represent the Rock Creek watershed. Figure 13.2 shows the watershed model within the $\mathrm{V} f l{ }^{\mathrm{TM}}$ model interface. Each grid cell is connected by a finite element that conveys either overland or channel runoff to its downstream neighbor by means of the kinematic wave analogy. Depending on the interest in the model results, either event or long-term continuous simulation is performed using lumped or distributed rainfall input. Event-based modeling is performed to gain a better understanding of the distribution of rainfall and runoff at sample locations where grab samples are taken for water quality 
analysis. Long-term continuous simulation tracks soil moisture and runoff during the period of simulation with the goal of determining site-specific runoff and loading associated with specific landuse categories and development.

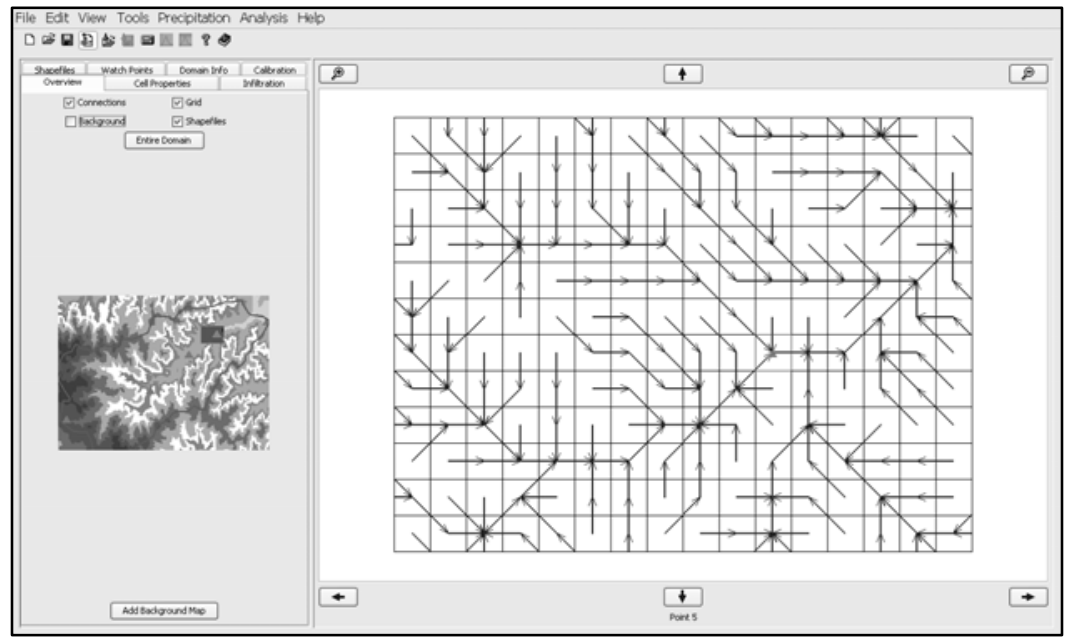

Figure 13.2 Rock Creek watershed displayed in the model interface.

Rain gauge data may be input directly to the model for event or longterm continuous simulation. Before using radar rainfall as input, radar estimates of rainfall should be corrected for bias (systematic overestimation and/or underestimation), by calibrating with gauge data. Application and statistical analysis of radar data corrected with rain gauge accumulations for characterization of urban storm and sanitary sewer system capacity are described in Vieux and Vieux (2005) and in Einfalt et al. (2004). Calibration is applied by using the ratio between the sum of each gauge divided by the sum of the sampled radar values over each gauge. The radar/gauge pairs are used as the multiplicative factor that adjusts the radar. A selected storm total map derived from gauge-adjusted radar is shown in Figure 13.3.

Once bias is removed by adjusting the radar accumulation, the rain gauge data is expected to agree with radar event accumulations. Bias corrected radar rainfall produces more accurate streamflow predictions than unadjusted radar rainfall input (Vieux and Bedient, 2004). The relative agreement can be seen in the scatterplot of gauge and radar rainfall accumulations for this event shown in Figure 13.4. 


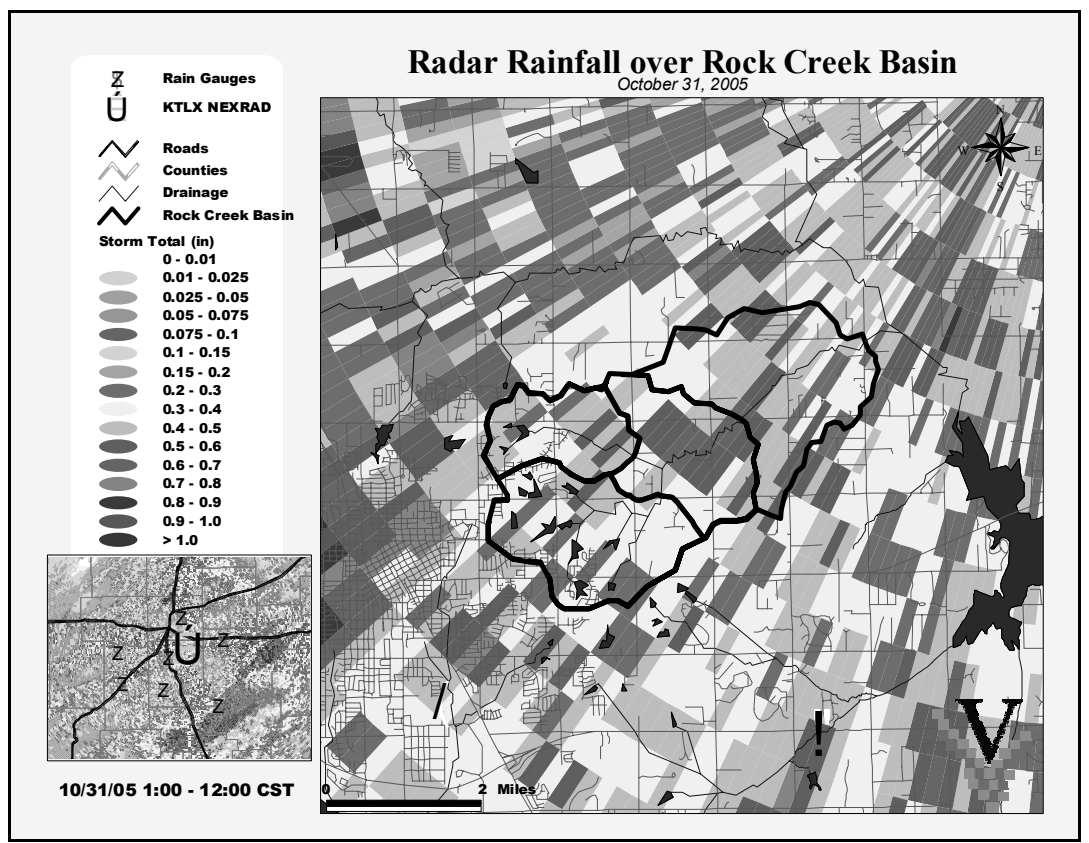

Figure 13.3 Storm total map over Rock Creek Watershed.

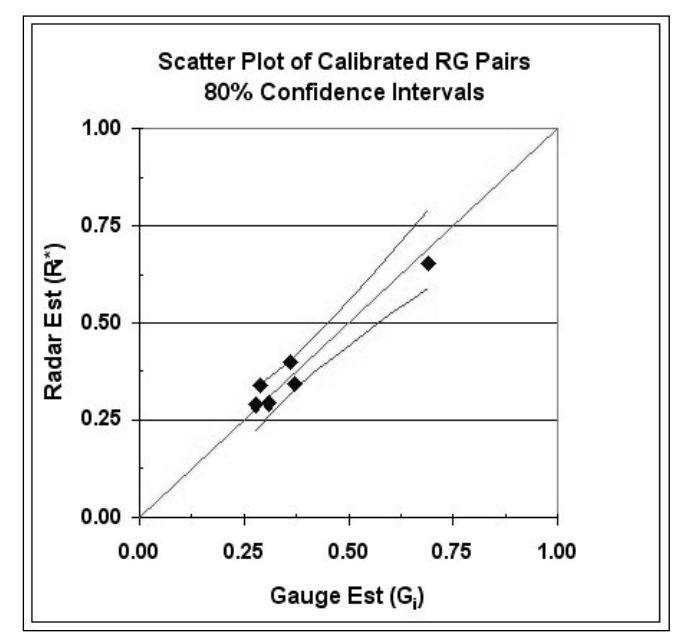

Figure 13.4 Rainfall accumulation scatter plot for gauge and radar 
Some departures are apparent, which may be due to local wind eddies affecting gauge efficiency, scale differences between the gauge orifice size ( $\sim 8$-in) and the radar sample volume $\left(1^{\circ} \times 1 \mathrm{~km}\right)$, and updrafts and downdrafts that decelerate or accelerate the local rainfall rates. Even with these differences between the observational systems (gauge and radar) in terms of measurement method and scale, the agreement is close as evidenced by the coefficient of determination, $\mathrm{R}^{2}=0.93$, and by the $80 \%$ confidence intervals shown in Figure 13.4.

\subsubsection{Long-term Simulation Procedure}

Long-term estimates of loading from nutrients and other water quality parameters is estimated by simulating ten years of hourly gauge rainfall. Modeled runoff is generated using land use parameters that are representative of the baseline and development scenarios. Loading is the mass of nutrients expected from a given watershed or unit area, which combines event mean concentration and runoff volume. Loading depends on runoff volume, supply and mobilization, and concentration, which are variable over time and space. Runoff volume and concentration may be correlated, either negatively or positively depending on the source and availability of the constituent in the runoff, e.g., sediment mobilized from eroded soils or street wash off. Where there is no limit to the supply of a constituent being dissolved or transported by surface runoff, the loading will increase with increased runoff. Where the supply or mobilization is limited, then loading may decrease with increased runoff. For purposes of this simulation, the concentration is assumed constant for the event and land use type, which is defined as the event mean concentration (EMC) for the land use type. The loading rate, $L_{t}$, is the product of the concentration and flow rate that is the average for any given event defined as:

$$
L_{t}=Q_{t} \cdot \hat{C}_{t}
$$

where:

$$
\begin{aligned}
& \hat{C}_{t}=\text { event mean concentration for event } t, \text { and } \\
& Q_{t},=\text { event flow rate }
\end{aligned}
$$

The EMC for each constituent examined is assigned based on the dominant land use type above a given sample location in the watershed. A related part of this study is the event sampling of constituents at these same locations. 
Model results are examined to evaluate the relative magnitude of loading from the development scenarios.

The following sections present the results of event and long-term continuous simulation for the subject watershed.

\subsection{Results and Discussions}

The purpose of the long-term simulations is to identify the relative magnitude of development scenarios in terms of nutrient loading. The eventbased simulation is performed to evaluate the magnitude of the runoff during a sampled event taken from the rising or recession limb of the hydrograph. Rather than base projections on assumed rainfall-runoff coefficients, specific information is derived for each scenario at the watershed outlet. Because the model is distributed, any potential location could be selected to obtain the loading and runoff. First, the long-term continuous simulation is considered, and then followed by the event-based simulation results.

\subsubsection{Loading from Development Scenarios}

The runoff volume accumulated for each development scenario is presented in Figure 13.5. A noticeable change in accumulation is witnessed by the change in slope evident in the year 2000 with slower rates of increase thereafter. The change in slope is due to climatic variability of rainfall that began with a drought in 2000, and subsequent high variability. Table 13.3 presents the runoff and loading rates derived from this analysis for each scenario. These loading rates are expressed on a per unit area basis. The runoff and total phosphorus and nitrogen are reported in Table 13.3 for the end of the simulation period, which is 2005 .

Table 13.3 Expected runoff and loading for each scenario derived from long-term continuous simulation.

\begin{tabular}{cccc}
\hline Land use & Cumulative Runoff (in) & $\begin{array}{c}\text { TP } \\
\text { (lbs/ac/yr) }\end{array}$ & $\begin{array}{c}\text { TKN } \\
\text { (lbs/ac/yr) }\end{array}$ \\
\hline Baseline & 74 & 0.4 & 1.3 \\
Scenario 1 & 93 & 0.5 & 1.9 \\
Scenario 2 & 115 & 0.7 & 2.7 \\
Scenario 3 & 139 & 0.8 & 3.7 \\
\hline
\end{tabular}




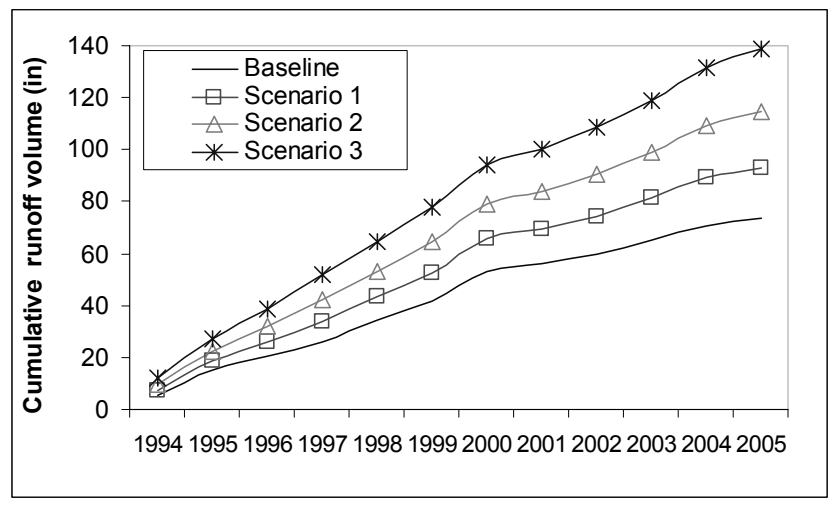

Figure 13.5 Runoff for baseline and development scenarios.

The loading rates for the baseline condition are the lowest, which then increase monotonically with increased development in each scenario. During the ten-year period, total Kjeldahl Nitrogen (TKN) nearly triples in annual loading, whereas total phosphorus (TP) loading doubles in magnitude. The simulated increase in runoff volume, due to development, is 1.9 times the baseline conditions. The increase in TP and TKN are not of the same magnitude. This change in the TP to TKN ratio could affect strategies for control or mitigation of algae in the receiving water body. As more events are sampled, these loading rates will be refined for projection of water quality impacts. From these results, non-point source loading estimates and control strategies can be formulated and compared with expected impacts of urban development using watershed specific climate and physical characteristics (USEPA, 2002; and 2005).

\subsubsection{Event Modeling}

Event-based modeling pertains to sampled events when water quality samples are taken at pre-determined locations within the watershed during a storm event. Continuous sampling has not been performed to date where an entire hydrograph will be sampled to obtain representative concentrations and EMC values. Results from the sampled events are compared to the median EMC values in the NSQD. The major land use of each sample site is used to compare its parameter values to those of the NSQD. The comparison of the sampled results from the watershed and the NSQD EMC medians are plotted in Figure 13.6. 


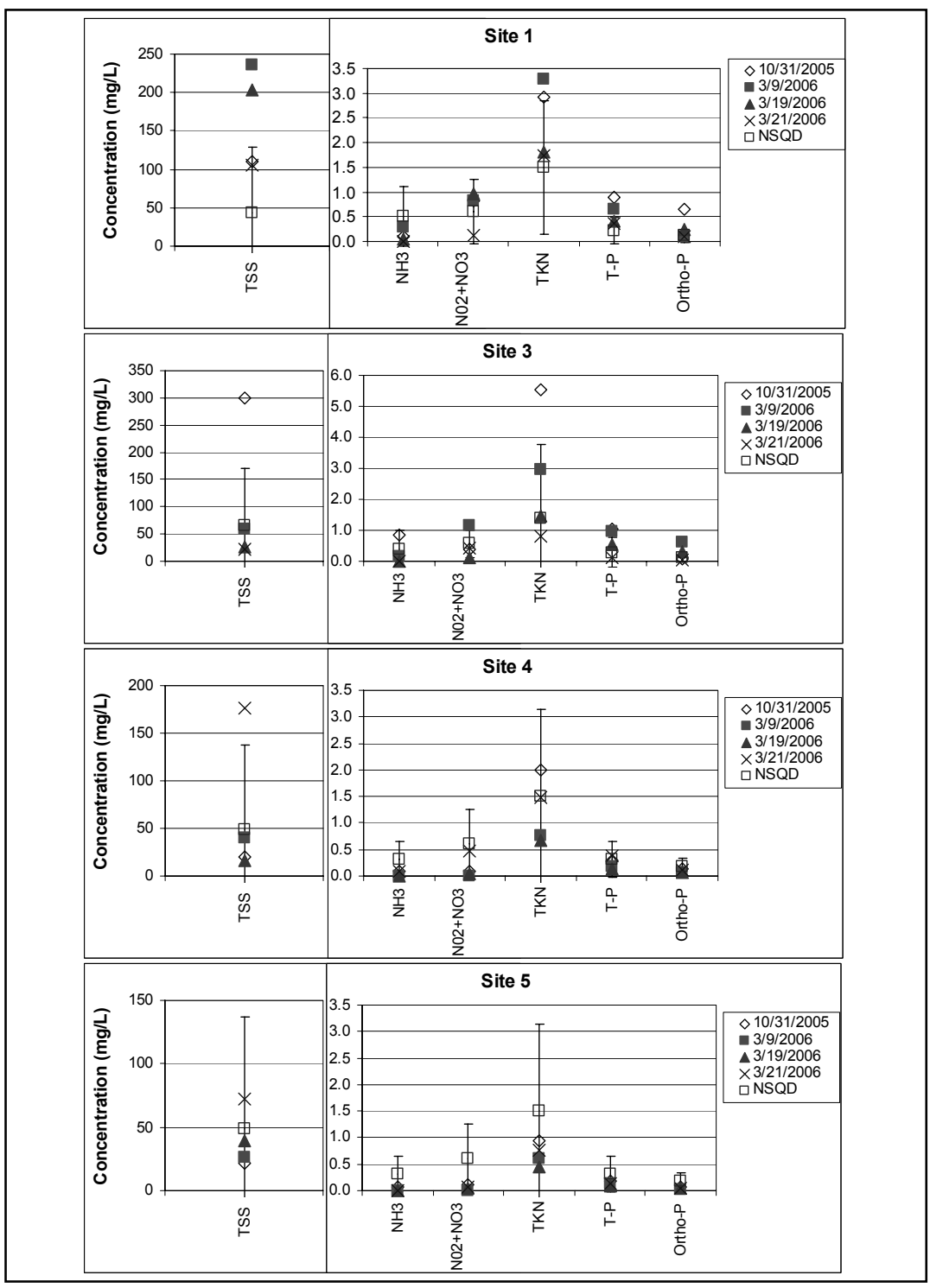

Figure 13.6 Sample concentrations for rainfall events for runoff constituents with error bars indicating \pm 1 standard deviation from the NSQD. 
Of the events considered, ammonia and nitrate plus nitrite at most sites are lower than the NSQD median values. The TP and TKN at Site 3 are higher than the NSQD median values in 3 out of 4 of the events. TP and TKN are the highest for all events at Site 1. Overall, among the sample sites, Site 5 has the lowest concentration of parameters in most of the events which is likely due to its location that includes a large percentage of undeveloped drainage area. Sites 1 and 3 appear to have the highest parameter levels more often than other sites. They are the most developed under current conditions. The concentrations derived from samples taken during the events can be used to refine the loading estimates for this watershed. By combining sampled events with model simulations, more representative loading can be derived for planning and management of development under various scenarios.

\subsection{Conclusions}

Development that leads to increased commercial and residential land use types also results in more runoff volume and increases in TKN and TP nutrient constituents, though in different proportions. Sites 1 and 3 show the highest concentration for most of the runoff components, including suspended solids and nitrogen and phosphorus species, for the majority of sampled the events. The dominant land use category is Commercial at Site 1, and Residential at Site 3. The commercial and residential land use categories, Sites 1 and 3, show the highest levels of nitrogen and phosphorus concentrations. Although sample sites with larger relative areas of commercial and residential land use categories are located further upstream, the sample sites downstream do not reflect high concentration values. This reduction in concentration at downstream locations is likely due to deposition and dilution from runoff derived from relatively natural conditions without development.

The selected modeling approach allows for simulation of current conditions and projected land use change at specific locations within a watershed. The use of rainfall input derived from rain gauge and radar sources supports event- based and continuous long-term simulations for projected urban development scenarios. Considering current conditions as the baseline condition, partial and full-development scenarios are evaluated. Long-term rainfall-runoff simulations and resulting pollutant loading rates indicate that TKN has the largest increase in annual loading due to 
development. Under full development, during a ten-year period TKN nearly triples in annual loading, whereas, phosphorus doubles in magnitude. The simulated increase in runoff volume, due to development, is 1.9 times the baseline conditions. These results help identify future effects on receiving water bodies and guide expectations regarding effects of development on local stormwater quality management.

\section{References}

Einfalt, T., K. Arnbjerg-Nielsen, D. Faure, N.-E. Jensen, M. Quirmbach, G. Vaes, B.E. Vieux, C. Golz, 2004. Towards a Roadmap for Use of Radar Rainfall Data in Urban Drainage. J. of Hydrology. 299(3-4), pp. 186-202. Special Issue on Urban Hydrology. Maestre, A. and R.E. Pitt. 2005. "Identification of Significant Factors Affecting Stormwater Quality Using the National Stormwater Quality Database." Journal of Water Management Modeling R225-13. doi: 10.14796/JWMM.R225-13.

Pitt, R., A. Maestre, R. Morquecho, T. Brown, C. Swann, K. Cappiella, and T. Schueler. (2003). Evaluation of NPDES Phase 1 Municipal Stormwater Monitoring Data, Available on the Internet at: http://www.epa.gov/owow/nps/natlstormwater03/28Pitt.pdf. Last accessed 10/04/05.

USEPA, 2005. Urbanization and Streams: Studies of Hydrologic Impacts. Available on the Internet at: http:/www.epa.gov/owow/nps/urbanize/report.html. Last Accessed $8 / 30 / 2005$.

USEPA, 2002. National Management Measures to Control Nonpoint Source Pollution from Urban Areas-Draft. EPA 842-B-02-003. U.S Environmental Protection Agency

Vieux. B.E., 2004. Distributed Hydrologic Modeling Using GIS. Kluwer Academic Publishers, Norwell, Massachusetts, Water Sci. Tech. Series, No. 48, Second Edition. Vol. 48. ISBN 1-4020-2459-2, p. 289. CD-ROM including model software and documentation.

Vieux, B.E., and Bedient, P.B., 2004. Assessing urban hydrologic prediction accuracy through event reconstruction. Journal of Hydrology 299(3-4):217-236.

Vieux, B.E., and Moreda, F.G., 2003. Ordered Physics-Based Parameter Adjustment of a Distributed Model. In, Advances in Calibration of Watershed Models, Edited by Q. Duan, S. Sorooshian, H.V. Gupta, A.N. Rousseau, R. Turcotte, Water Sci. and Appl. Series, 6, American Geophysical Union, ISBN 0-87590-355-X: 267-281.

Vieux, B.E., and J.E. Vieux, 2005. Statistical evaluation of a radar rainfall system for sewer system management. J. of Atmospheric Research, 77 (2005) 322- 336. 